\title{
The modified Senning operation for cavopulmonary connection with autologous tissue
}

\begin{abstract}
A modified Senning technique was used for intraatrial channeling of the systemic venous blood into the pulmonary arteries to create a Fontan circulation in 26 children, six with tricuspid atresia and 20 with complex congenital heart disease. In this technique a flap of atrial free wall tissue is used to create an atrial tunnel without artificial material. Eight patients had subaortic stenosis and required a DamusKay-Stansel procedure, in addition. Early mortality was two of 26 and late mortality one of 26. Pleural effusion was encountered in 17 of 26 patients, of whom four had a pericardial effusion, in addition. One patient required pacemaker implantation for complete atrioventricular block. Follow-up ranged from 2 months to 5 years. In this period the ability level index rose by one level. No thrombi were encountered in the right atrium/cavopulmonary tunnel. One patient required antiarrhythmic medication. Protein-losing enteropathy was diagnosed in one patient. Conclusion: This modified Senning technique has the advantage of avoiding the use of prosthetic material in the creation of a Fontan circulation and the potential for fewer long-term complications. ( $J$ THORAC CardovasC SurG 1994;108:377-80)
\end{abstract}

Henry J. C. M. van de Wal, MD, PhD, Ronald F. Tanke, MD, and Mark J. Roef, MD Nijmegen and Utrecht, The Netherlands

$\mathrm{T}_{\mathrm{h}}$ he use of a direct cavopulmonary connection has been proposed for the creation of a Fontan-like circulation, on the basis of both theoretic and practical advantages. ${ }^{1-4}$ Intraatrial channeling of vena caval return has previously been described, with the use of pericardial baffles, Dacron or polytetrafluoroethylene tube grafts, and baffles cut from tube grafts. These materials do not grow and may obstruct flow as the child grows. We describe a technique, based on the Senning procedure, in which a flap of atrial free wall is used to create the inferior vena caval (IVC) channel, and the use of prosthetic material is thereby avoided.

From the Departments of Cardiopulmonary Surgery and Paediatric Cardiology, Sint Radboud University Hospital, Nijmegen, and the Wilhelmina Children's Hospital, Utrecht, University Utrecht, The Netherlands.

Received for publication Dec. 22, 1992.

Accepted for publication Jan. 18, 1994.

Address for reprints: Henry J. C. M. van de Wal, MD, PhD, Children's Heart Center, Wilhelmina Children's Hospital, Utrecht University, P.O. Box 18009, 3501 CA Utrecht, The Netherlands.

Copyright 1994 by Mosby-Year Book, Inc.

0022-5223/94 \$3.00+0 $\quad \mathbf{1 2 / 1 / 5 4 5 9 6}$

\section{Patients and methods}

During a 5-year period between 1987 and 1991, 26 children, six with tricuspid atresia and 20 with complex cardiac anomalies, underwent creation of an autologous atrial tunnel as part of a modified total cavopulmonary connection. Eight of these patients had subaortic stenosis, in addition. Twenty-two patients had had a previous operation: aortopulmonary shunt $(n=11)$ and banding of the main pulmonary artery $(n=11)$. Before the operation, 24 of the patients were in sinus rhythm, one had an atrial rhythm, and one had a sick sinus syndrome. Characteristics of the patients are given in Table I.

A median sternotomy was performed in all patients, followed by dissection of the aortic arch, main pulmonary artery, and right pulmonary artery up to the hilum, and the brachiocephalic vein, azygos vein, and superior vena cava (SVC). The SVC and IVC were cannulated with angled metal cannulas (DLP Inc., Walker, Mich.).

To avoid the use of foreign material as much as possible, we developed our technique over the past years to include the creation of an autologous intraatrial tunnel. This was achieved by incision of the right atrial wall in a trapezoid fashion, after exposure of the atrial cavity. The right atrial wall flap thus obtained was sutured to the right of the coronary sinus, anterior to the right atrioventricular valve anulus, to avoid the atrioventricular node. The suture line was continued, incorporating the intraatrial flap in the atrial wall flap (Fig. 1). In 16 patients this left the coronary sinus draining into the left atrial cavity. Continuation of the IVC was achieved with the longitudinal incision of the right atrial appendage, which was folded downward to 
a
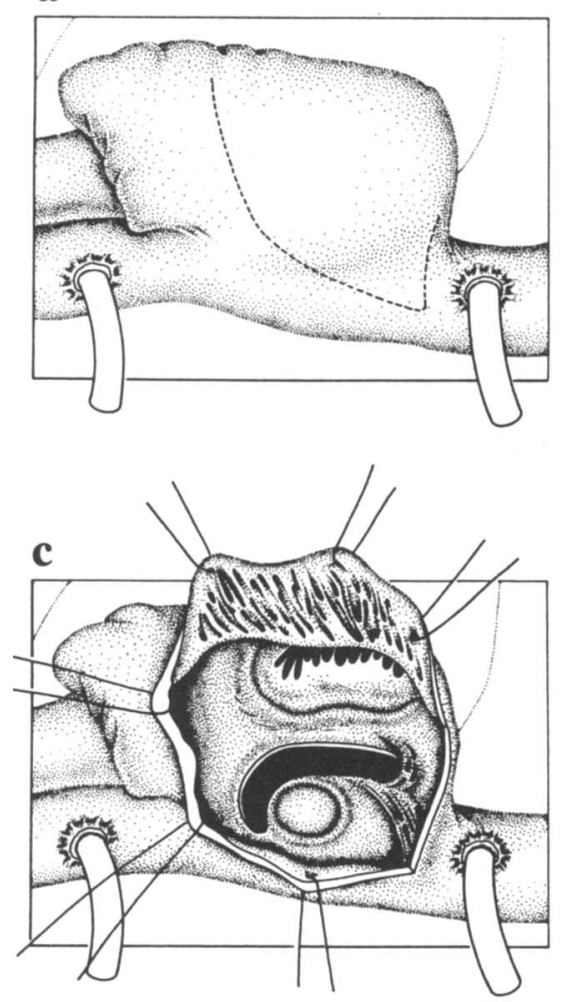
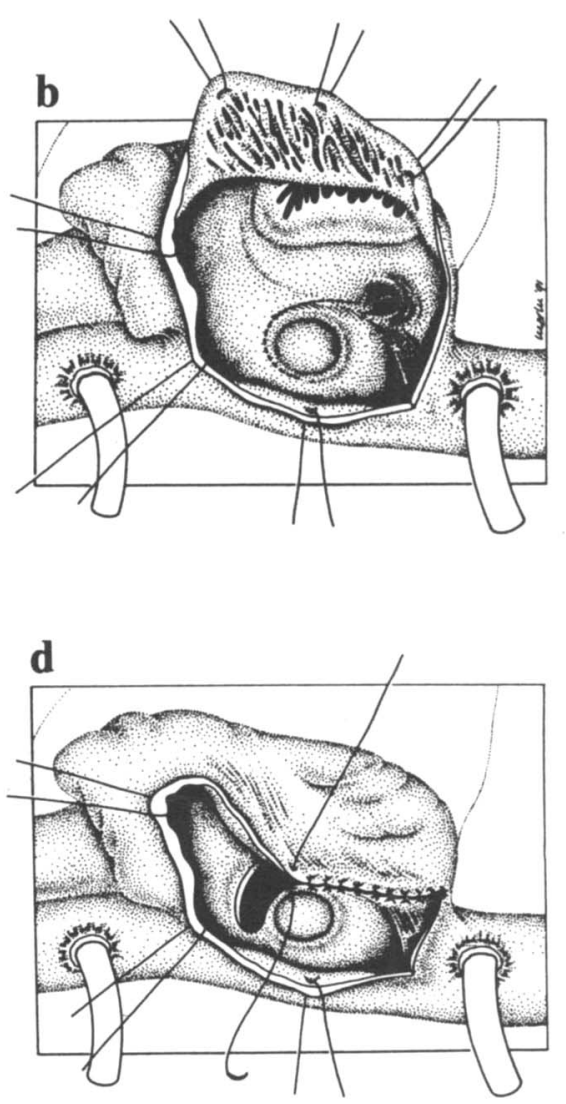

Fig. 1. Homologous atrial tunnel for direct cavopulmonary connection. a, Right atrial incision. b, Incision of atrial septum. c, Atrial septum opened. d, Reconstruction of new "atrial septum."

Table I. Patient characteristics at operation

\begin{tabular}{lcc}
\hline & Mean $\pm S D$ & Range \\
\hline Age (yr) & $6.1 \pm 4.5$ & $1-16$ \\
Length $(\mathrm{cm})$ & $112 \pm 29$ & $75-183$ \\
Weight $(\mathrm{kg})$ & $21.2 \pm 14.3$ & $8-65$ \\
\hline
\end{tabular}

$S D$, Standard deviation.

obtain a smooth and straight channel. If necessary, the trabeculations of the atrial appendage were removed. Additional autologous pericardial tissue was generally not required for this maneuver. To obtain the cavopulmonary connection, we first transected the SVC just above the right atrium. The roof of the right atrium was opened at this site by an incision in an anterior and medial direction (carefully avoiding the sinus node arteries), so as to enlarge the diameter of the opening and to achieve as large an anastomosis as possible. The main pulmonary artery was then transected and its cardiac end closed directly. The opening in the pulmonary artery was enlarged by an incision toward the right, and an end-to-end anastomosis was made between the right atrial roof and pulmonary artery. The distal end of the SVC was anastomosed end to side to a wide defect created in the superior aspect of the right pulmonary artery. In eight patients with subaortic obstruction, a Damus-Kay-Stansel procedure was performed as well.

\section{Results}

The mean extracorporeal circulation time was $208 \pm 82$ minutes and the mean aortic crossclamp time was $137 \pm 54$ minutes. Mortality within 30 days after the operation included one perioperative and three postoperative deaths. The causes were intractable cardiac failure in two and septic shock in two. Morbidity resulting from pleural effusion for longer than 7 days was seen in 17 $(77 \%)$ patients, of whom four $(18 \%)$ in addition had a pericardial effusion. A medium-chain triglyceride diet was instituted successfully in 12 patients (48 to 53 days). Two patients in whom conservative treatment failed required pleurectomy and ligation of the thoracic lymphatic duct, and one required pleurectomy alone. Isolated pericardial effusion was encountered in one patient and treated conservatively. Other associated complications included diaphragmatic paralysis in four of $24(17 \%)$, which was treated conservatively in all, and sepsis in five 

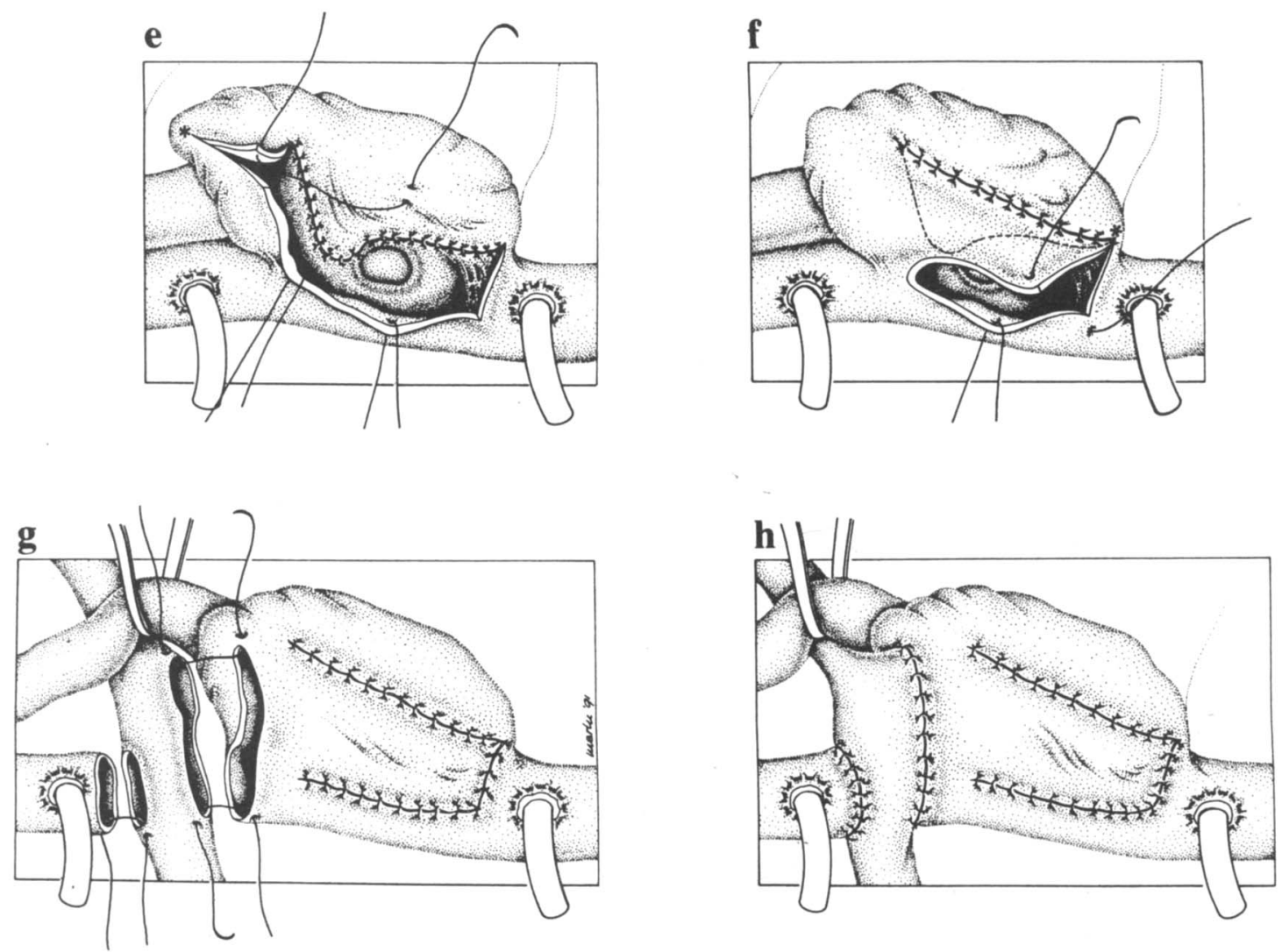

Fig. 1. Cont'd. e, Reconstruction of atrial septum completed. Remodeling of atrial appendage to form atrial tunnel. $\mathbf{f}$, Reconstruction of paraatrial tunnel. $\mathbf{g}$, Atriopulmonary connection is constructed by use of right atrial roof. h, SVC is connected by end-to-side anastomosis.

of $24(21 \%)$, all with different microorganisms. Immediately after the operation a change in rhythm was observed in four patients, in whom an atrial rhythm developed, and in one who required pacemaker implantation after concomitant atrioventricular valve replacement. Discharge therapy included antiarrhythmic medication in one of 21 , inotropic support in 10 of 21, and diuretics in 16 of 21 .

\section{Follow-up}

At follow-up one late death occurred. Follow-up ranged from 1 month to 4 years 7 months (mean 6 months) and included physical examination, electrocardiogram, chest roentgenogram, and two-dimensional echo-Doppler studies. Dyspnea, edema, ascites, pericardial fluid, and exercise tolerance were measured by the ability index ${ }^{5}$ before and after the operation and showed an increase of one level after the operation. No thrombus of the right atrium-caval tunnel or residual shunting was observed on echo-Doppler investigation. A Holter monitor showed that one patient known to have sinus rhythm before and immediately after the operation later had first-degree atrioventricular block. The four patients who had an atrial rhythm immediately after the operation regained sinus rhythm, whereas the rhythm in the one patient with sick sinus syndrome remained unchanged. One child had a persistent protein-losing enteropathy. Withdrawal from diuretic therapy was attempted in all patients and was successful in 10 .

\section{Discussion}

Although total cavopulmonary anastomosis has been in vogue for only a short time, it has many theoretic and practical advantages over the more conventional modified Fontan procedures that use an atriopulmonary connection. Reduced loss of energy by direct channeling of blood to pulmonary arteries has been suggested. ${ }^{3}$ In some patients with complex cardiac anomalies, the total cavopulmonary anastomosis may be the only possible method of separating the two circulations. ${ }^{6}$ Various techniques for the construction of this intraatrial tunnel have been described. Most of these include the incorporation of prosthetic material, specifically when dealing with cases 
of complex congenital cardiac anatomy in which extensive baffeling or channeling of IVC blood into the SVC is required. The incorporation of prosthetic material, however, is likely to cause an increased likelihood of pulmonary pathway obstruction, as has been shown in other techniques for Fontan connection. ${ }^{7}$

We describe a method of direct cavopulmonary connection in infants and small children that avoids or minimizes the use of prosthetic and therefore growth-limiting materials. Although long-term follow-up on the growth of autogenous atrial channels has not been obtained, we are forecasting a positive experience with regard to growth of the atrial tunnel, similar to that found in the Senning procedure used for transposition of the great arteries. In addition, the described technique has the reported advantage of incorporating the coronary sinus in the low-pressure left atrium. ${ }^{8}$

A theoretic disadvantage is the potential for arrhythmias should the sinus node artery be damaged at the time of atrial incision. As a result of rhythm disturbances, Puga, Chiavarelli, and Hagler ${ }^{1}$ changed their paraatrial approach to an SVC reconstruction. However, even after the Senning operation and an extended vertical transseptal approach for mitral valve exposure, ${ }^{9}$ rhythm disturbances are encountered remarkably infrequently. Immediately after the operation four of 22 patients lost sinus rhythm and acquired an atrial rhythm. One patient required pacemaker implantation for complete atrioventricular block after concomitant atrioventricular valve replacement. In the survivors, follow-up with a Holter monitor showed return to sinus rhythm from atrial rhythm. One patient had first-degree atrioventricular block and is currently on a long-term regimen of antiarrhythmic medication.

Another potential risk is residual shunting, especially in the trabecular portion of the right atrium. In general, the smooth anterior wall of the right atrium is used for the new atrial septum and the trabeculation of the atrial appendage is removed before the channel is constructed. No shunting at the atrial level or leakage from the suture line of the caval channel was detected in any patients. The Damus-Kay-Stansel procedure had to be performed in eight (32\%) children for subaortic stenosis. Extracorporeal circulation and aortic crossclamp time were consid- erably longer in this group. However, no significant difference could be found for morbidity, mortality, or complications.

Sepsis was encountered in six children. In three irreversible septic shock occurred immediately after the operation and was diagnosed from the clinical picture, together with laboratory parameters (leukocytosis and thrombocytopenia). In two others sepsis developed late, unrelated to the operation. Only one patient with staphylococcal sepsis survived.

Long-term follow-up is still required to ascertain whether rhythm disturbances will occur with this procedure. Thus far, echo-Doppler studies have not shown any hemodynamic obstruction in the caval system.

\section{REFERENCES}

1. Puga FJ, Chiavarelli M, Hagler DJ. Modifications of the Fontan operation applicable to patients with left atrioventricular valve atresia or single atrioventricular valve. Circulation 1987;76(Suppl):III53-60.

2. Matsuda H, Kawashima Y, Kishimoto H. Problems in the modified Fontan operation for univentricular heart of the right ventricular type. Circulation 1987;76(Suppl):III45-52.

3. de Leval M, Kilner P, Gewillig M, Bull C, McGoon DC. Total cavopulmonary connection: a logical alternative to atriopulmonary connection for complex Fontan operations. J THORAC CARDIOVASC SURG 1988;96:682-95.

4. Jonas RA, Castaneda AR. Modified Fontan procedure: atrial baffle and systemic venous to pulmonary artery anastomotic techniques. J Cardiac Surg 1988;3:91-6.

5. Somerville J. Congenital heart disease in the adolescent. Arch Dis Child 1989;64:771-3.

6. Chopra PS, Rao PS. Corrective surgery for tricuspid atresia: Which modification of Fontan-Kreutzer procedure should be used? A review. Am Heart J 1992;123:758-67.

7. Fernandez G, Costa F, Fontan F, Naftel DC, Blackstone EH, Kirklin JW. Prevalence of reoperation for pathway obstruction after Fontan operation. Ann Thorac Surg 1989; 48:654-9.

8. Ilbawi MN, Idriss FS, Muster AJ, et al. Effects of elevated coronary sinus pressure on left ventricular function after the Fontan operation. J ThORAC CARDiovasc SuRg 1986; 92:231-7.

9. Alfieri O, Sandrelli L, Pardini A, et al. Optimal exposure of the mitral valve through an extended vertical transeptal approach. Eur J Cardiothorac Surg 1991;5:294-9. 